\title{
Midazolam anesthesia protects neuronal cells from oxidative stress-induced death via activation of the JNK-ERK pathway
}

\author{
JING-YU LIU ${ }^{1}$, FENG GUO ${ }^{2}$, HONG-LING WU ${ }^{3}$, YING WANG ${ }^{1}$ and JIN-SHAN LIU ${ }^{1}$ \\ ${ }^{1}$ Department of Anesthesiology, Dongying People's Hospital; ${ }^{2}$ Department of Anesthesiology, \\ Dongying District People's Hospital; ${ }^{3}$ Department of Anesthesiology, \\ Kenli People's Hospital, Dongying, Shandong 257091, P.R. China
}

Received September 23, 2015; Accepted September 22, 2016

DOI: $10.3892 / \mathrm{mmr} .2016 .6031$

\begin{abstract}
Midazolam is an anesthetic agent commonly used during clinical and surgical procedures, which has been shown to exert ROS-suppressing and apoptosis-modulating pharmacological activities in various cellular systems. However, the effects of midazolam on oxidative stress in neuronal cells require elucidation. The present study investigated the effects of midazolam on buthionine sulfoximine (BSO)- and hydrogen peroxide $\left(\mathrm{H}_{2} \mathrm{O}_{2}\right)$-induced oxidative stress in primary cortical neuronal cells. In addition, the effects of midazolam on middle cerebral artery occlusion (MCAO) in mice and on ethanol-induced neuroapoptosis in the brains of neonatal mice were determined. Subsequently, cell viability was detected using the MTT assay; intracellular reactive oxygen species (ROS) generation was determined using the 2',7'-dichlorodihydrofluorescein diacetate method with confocal microscopy; terminal deoxynucleotidyl transferase dUTP nick end labeling (TUNEL) staining was conducted to detect apoptotic cells; immunohistochemistry was performed to detect activated caspase-3; neuronal deficit and infarct volume analyses were conducted; and quantitative polymerase chain reaction and western blotting were performed to detect the expression levels of genes and proteins associated with apoptosis and cell survival pathways. The results demonstrated that BSO $(10 \mathrm{mM})$ and $\mathrm{H}_{2} \mathrm{O}_{2}(1 \mathrm{mM})$ suppressed proliferation of cortical neuronal cells by inducing apoptosis. These effects were suppressed following treatment with midazolam in a dose-dependent manner. In addition, $\mathrm{BSO}$ and $\mathrm{H}_{2} \mathrm{O}_{2}$ induced ROS generation in neuronal cells; however, this was effectively suppressed by midazolam $(100 \mu \mathrm{M})$. Beneficial synergistic effects were detected when midazolam was used in combination with the
\end{abstract}

Correspondence to: Dr Jing-Yu Liu, Department of Anesthesiology, Dongying People's Hospital, 317 Nanyi Road, Dongying, Shandong 257091, P.R. China

E-mail: jyliuanesth@hotmail.com

Key words: anesthesia, midazolam, apoptosis, oxidative stress, neurodegeneration, reactive oxygen species known antioxidant trolox. $\mathrm{BSO}$ and $\mathrm{H}_{2} \mathrm{O}_{2}$ also suppressed the protein expression levels of c-Jun N-terminal kinases (JNK), phosphorylated (p)JNK, extracellular signal-regulated kinases (ERK)1/2, pERK1/2, AKT and nuclear factor- $\kappa$ B; however, expression was recovered following treatment with midazolam. Midazolam also activated protein kinase $\mathrm{C}-\varepsilon$, which was suppressed by BSO, in cortical neuronal cells. In MCAO mice, midazolam post-conditioning significantly suppressed infarct size and reduced the number of TUNEL-positive cells. In addition, the expression levels of caspase-3 and poly (ADP-ribose) polymerase were suppressed in a dose-dependent manner. In neonatal mice, midazolam reduced ethanol-induced activated caspase-3 staining and apoptotic TUNEL staining. The results of the present study demonstrated that midazolam may protect against neuronal degeneration and neuroapoptosis induced by physiological and oxidative stress.

\section{Introduction}

Neuronal cells in the developing brain and central nervous system are markedly sensitive to anesthetic agents. Anesthetics are clinical drugs used during surgical and clinical procedures to induce sedation, and are commonly regarded as safe. Although the majority of anesthetics have been confirmed to be safe, some anesthetics exert neurotoxic effects, even at a normal clinical dose. Contrasting reports exist on the effects of anesthetics on neuronal physiology and growth. Several anesthetics and anticonvulsant agents have been reported to exert neuronal cytotoxicity, neuronal dysfunction, and apoptosis-inducing activity in vitro and in vivo $(1,2)$. In previous studies, primary neuronal cells and neonatal mice treated with ketamine and propofol exhibited blunted dendritic growth, reduced dendritic spines and arborization (2-4). In addition, administration of isoflurane to neuronal precursor cells derived from neonatal rats resulted in a reduced proliferative capacity (5). Spinal cord neuronal apoptosis has also been induced by intrathecal administration of ketamine, but not morphine (6). Conversely, in other studies, neonatal mice exposed to anesthetics, including isoflurane, propofol and midazolam, exhibited reduced neuronal cell death, and dendritic alterations were histologically improved alongside increased dendritic spine density $(7,8)$. Furthermore, spinal 
administration of the anesthetic bupivacaine has been shown to exert no effect on neuronal apoptosis and locomotor activity in rats (9).

The immature developing brain passes through various neurodegenerative processes, including apoptosis, as part of normal development; however, previous reports have suggested that anesthetic agents, anticonvulsant drugs and ethanol may accelerate normal neuronal apoptosis (1-4,6). It has previously been reported that anesthetics, such as isoflurane and midazolam, provide protection against neuronal degeneration and apoptosis, improve histological parameters, and enhance behavioral and locomotor performance in neonatal rats (2). The dose and duration of anesthetic exposure has an important role in neuronal histology and cell growth. Continuous administration of ketamine to rat pups for $9 \mathrm{~h}$ resulted in poor feeding behavior and increased neurodegeneration, whereas single doses of ketamine exhibited no such effect (10). In addition, propofol infusion may exert protective effects via effectively reducing hepatic ischemia/reperfusion injury in rats by decreasing cellular apoptosis (11). Propofol, with its antioxidant and anti-inflammatory activity, is considered a potential hepatoprotective anesthetic in liver surgery. Anesthetics associated with oxidative stress predominantly induce $\mathrm{Ca}^{2+}$ release from intracellular stores, including the rough endoplasmic reticulum (12). Early indicators of the effects of anesthetics-mediated apoptosis include reactive oxygen species (ROS) accumulation, mitochondrial uncoupling and mitochondrial membrane depolarization. These alterations cause ROS generation, and damage to the mitochondria and endoplasmic reticulum, thus inducing cell death when administered in excess.

Midazolam, which is a $\gamma$-aminobutyric acid $\mathrm{A}\left(\mathrm{GABA}_{\mathrm{A}}\right)$ receptor agonist of the benzodiazepine class, is a commonly used anesthetic for the induction of sedation. Midazolam administration has been shown to preserve dendritic structures, and does not affect neuronal development during anesthesia (4). Conversely, midazolam activates apoptosis of cancer cells of various origins, including hematologic, ectodermal and mesenchymal cells $(2,13,14)$. Midazolam predominantly acts as an agonist for $\mathrm{GABA}_{\mathrm{A}}$ receptor and peripheral-type benzodiazepine receptors (PBRs) $(15,16)$. PBRs transduce cellular functions, including cell growth and death, proliferation, and oxidative processes. The present study investigated the effects of midazolam on oxidative stress in neuronal cells and elucidated the mechanism underlying these effects. Midazolam was shown to exert protective effects against oxidative insults in neuronal cells in vitro and in vivo via the suppression of ROS and prevention of neuronal cell death. Therefore, the anesthetic midazolam, with its antioxidant and anti-apoptotic properties, may be considered a promising agent in clinical and surgical interventions.

\section{Materials and methods}

Preparation of primary cortical neuronal cell cultures. All animal experimental procedures were performed after obtaining ethical clearance and in accordance with the guidelines of the Animal Ethical Committee of the Dongying People's Hospital (Dongying, China). Primary cortical neuronal cultures were prepared from mice (obtained from the
Beijing Institute of Laboratory Animals, Chinese Academy of Medical Sciences, Beijing, China) according to standard protocol. Briefly, mouse neocortices were obtained from fetal mouse brains between embryonic day 14 and 15. Primary mixed cultures of neuronal and glial cells were prepared from cerebral cortices newborn mice pups obtained by mechanical dissociation without trypsin digestion. Neuronal cultures were grown on cover slips coated with polylysine in Dulbecco's modified Eagle's medium (Gibco; Thermo Fisher Scientific, Inc., Inc., Waltham, MA, USA) supplemented with $10 \%$ (v/v) fetal bovine serum (FBS; Thermo Fisher Scientific, Inc.) at $37^{\circ} \mathrm{C}$ in a $\mathrm{CO} 2$ incubator. Neocortices were grown in Eagle's minimum essential medium (MEM) (Gibco; Thermo Fisher Scientific, Inc.) supplemented with 5\% FBS, 5\% horse serum (Thermo Fisher Scientific, Inc.), $21 \mathrm{mM}$ glucose and $2 \mathrm{mM}$ glutamine in a humidified incubator containing 5\% $\mathrm{CO}_{2}$ at $37^{\circ} \mathrm{C}$. After 7 days, $10 \mu \mathrm{M}$ cytosine arabinofuranoside (Sigma-Aldrich; Merck Millipore, Darmstadt, Germany) was added to the cell cultures to prevent glial cell overgrowth. The cells were maintained for 2 weeks for experimental procedures.

Generation of oxidative stress in cortical neuronal cells. Cells were maintained as aforementioned, and oxidative stress was induced as follows: i) Cells were treated with $10 \mathrm{mM}$ buthionine sulfoximine (BSO; Sigma-Aldrich; Merck Millipore) for $6 \mathrm{~h}$, after which various concentrations of midazolam $(25,50$ and $100 \mu \mathrm{M}$; Tocris Bioscience, Bristol, UK) were added to the medium; or ii) cells were treated with $1 \mathrm{mM}$ hydrogen peroxide $\mathrm{H}_{2} \mathrm{O}_{2}$ (Merck Millipore) for $6 \mathrm{~h}$, after which various concentrations of midazolam were added to the medium. Mixed cortical cell cultures were then harvested and underwent further experimentation. Sterile normal buffered saline was used as a vehicle control throughout in vitro experiments.

Cell viability assay. Cell viability was assessed using the MTT Cell Proliferation Assay kit (Invitrogen; Thermo Fisher Scientific, Inc.) according to the manufacturer's protocol. Cells were treated with or without midazolam, in combination with either $\mathrm{BSO}$ or $\mathrm{H}_{2} \mathrm{O}_{2}$ in 96-well plates. In an experimental set, cells were pre-treated with $100 \mu \mathrm{M}$ of trolox (Sigma-Aldrich; Merck Millipore) for $2 \mathrm{~h}$. Cells were then treated with or without midazolam, in combination with either $\mathrm{BSO}$ or $\mathrm{H}_{2} \mathrm{O}_{2}$ in 96-well plates. After $48 \mathrm{~h}$ of treatment, $20 \mu \mathrm{lMTT}(2 \mathrm{mg} / \mathrm{ml})$ was added to each well and the plates were incubated for $2 \mathrm{~h}$ at $37^{\circ} \mathrm{C}$. The MTT-containing medium was then completely aspirated and $100 \mu \mathrm{l}$ dimethyl sulfoxide was added to each well to dissolve the formazan crystals. Subsequently, absorbance was measured at $570 \mathrm{~nm}$ using a microplate reader. The cell viability ratio was calculated and the value was presented as a percentage of control.

Determination of intracellular ROS levels. The production of ROS was measured using the 2',7'-dichlorodihydrofluorescein diacetate $\left(\mathrm{H}_{2} \mathrm{DCFDA}\right)$ assay kit (Invitrogen; Thermo Fisher Scientific, Inc.) according to the manufacturer's protocol. $\mathrm{H}_{2}$ DCFDA is a chemically-reduced form of fluorescein, which is used as an indicator of cellular ROS generation. The acetate groups are cleaved by intracellular esterases and oxidation, and the non-fluorescent $\mathrm{H}_{2}$ DCFDA is converted to the highly 
fluorescent 2',7'-dichlorofluorescein (DCF). Briefly, the cortical neuronal cells were treated with $\mathrm{BSO}$ or $\mathrm{H}_{2} \mathrm{O}_{2}$ with or without midazolam for $24 \mathrm{~h}$. Cells were then incubated with $10 \mathrm{mM}$ $\mathrm{H}_{2} \mathrm{DCFDA}$ for $30 \mathrm{~min}$ at $37^{\circ} \mathrm{C}$ in the dark. The cells were rinsed twice with fresh MEM supplemented with $1 \% \mathrm{FBS}$, and were washed three times with cold PBS. Subsequently, cells were fixed with $4 \%$ paraformaldehyde in PBS for 5 min at room temperature, washed twice with PBS and sealed with mounting media containing 4',6-diamidino-2-phenylindole (DAPI; Abcam, Cambridge, MA, USA). Images of the cells were captured using laser scanning confocal microscopy (Nikon Corporation, Tokyo, Japan).

Protein isolation and western blotting. Cell cultures were treated as aforementioned in 6-well plates prior to protein isolation. After treatment, cells were harvested, washed twice with ice-cold PBS and pelleted by centrifugation at 2,000 $\mathrm{xg}$ for $2 \mathrm{~min}$ at $4^{\circ} \mathrm{C}$. The cell pellets were lysed using cell lysis buffer containing $20 \mathrm{mM}$ Tris ( $\mathrm{pH} 7.5), 1 \mathrm{mM}$ EDTA, $150 \mathrm{mM} \mathrm{NaCl}, 2.5 \mathrm{mM}$ sodium pyrophosphate, $1 \%$ Triton $\mathrm{X}-100,1 \%$ sodium vanadate, $1 \mathrm{mM}$ phenylmethylsulfonyl fluoride and protein inhibitor cocktail (Invitrogen; Thermo Fisher Scientific, Inc.). The cells were incubated at $4^{\circ} \mathrm{C}$ for 30 min with intermittent vortex mixing. Subsequently, lysates were centrifuged at $10,000 \times \mathrm{g}$ for $10 \mathrm{~min}$ at $4^{\circ} \mathrm{C}$ and the supernatants were collected. Protein concentrations were estimated from the supernatants using the bicinchoninic acid protein assay kit (Pierce; Thermo Fisher Scientific, Inc.). Equal amounts of protein $(20 \mu \mathrm{g})$ in each sample were separated by $12 \%$ SDS-PAGE and proteins were transferred onto polyvinylidene fluoride transfer membranes (EMD Millipore, Billerica, MA, USA). Membranes were blocked in fat-free skimmed milk at room temperature for $2 \mathrm{~h}$ and were then washed twice with TBS-1\% Tween (TBST). Subsequently, membranes were incubated with protein-specific primary antibodies at $4^{\circ} \mathrm{C}$ overnight, after which they were washed three times with TBST at room temperature and were incubated with anti-mouse (cat. no. 7076) and anti-rabbit (cat. no. 7074) horseradish peroxidase (HRP)-conjugated secondary antibodies (1:5,000; Cell Signaling Technology, Inc., Danvers, MA, USA) for $90 \mathrm{~min}$ at room temperature. The blots were visualized using enhanced chemiluminescence solution (Invitrogen; Thermo Fisher Scientific, Inc.). All protein bands were semi-quantified using a densitometer and were analyzed using Bio-Rad Image Analysis Software version 4.1 (Bio-Rad Laboratories, Inc., Hercules, CA, USA). Primary antibodies used were as follows: Anti-caspase-3 (1:1,000; cat. no. 6992), anti-caspase-9 (1:1,000; cat. no. 9504), anti-poly (ADP-ribose) polymerase (PARP; 1:1,000; cat. no. 9542), anti-BH3 interacting-domain death agonist (Bid; 1:1,000; cat. no. 2003), anti-B-cell lymphoma 2 (Bcl2; 1:1,000; cat. no. 3498), anti-phosphorylated (p) extracellular signal-regulated kinases (ERK; 1:1,000; cat. no. 9101), anti-AKT (1:1,000; cat. no. 9272), anti-pAKT (1:2,000; cat. no. 4060), anti-c-Jun N-terminal kinases (JNK; 1:1,000; cat. no. 3708) and anti-pJNK (1:1,000; cat. no. 4668; Cell Signaling Technology, Inc.); anti-pERK (1:2,000; cat. no. sc-7383), anti-GAPDH (1:2,000; cat. no. sc-32233) and anti-protein kinase C (PKC)- $\varepsilon(1: 1,000$; cat. no. sc-1681; Santa Cruz Biotechnology, Inc., Dallas, TX, USA); and anti-nuclear factor (NF)- $\mathrm{B}$ (p65; 1:1,000; cat. no. NB100-2176; Novus Biologicals LLC, Littleton, CO, USA).

Middle cerebral artery occlusion (MCAO) in mice and midazolam administration. Female BALB/c mice (age, 5 weeks; weight, 20-24 g) were housed under standard laboratory conditions at $22-24^{\circ} \mathrm{C}$ with humidity at $50-60 \%$ and a 12-h light/dark cycle. Mice were allowed access to food and water ad libitum. The mice were randomly divided into four groups (n=20/group): Control group; MCAO group; $\mathrm{MCAO}+$ midazolam treatment group-1 (2 $\mathrm{mg} / \mathrm{kg})$; and $\mathrm{MCAO}+$ midazolam treatment group-2 (5 mg/kg). Midazolam was administered subcutaneously (s.c.) prior to MCAO. Transient MCAO in mice was induced according to the standard intraluminal suture method (17). Briefly, mice were anesthetized using $50 \mathrm{mg} / \mathrm{kg}$ pentobarbital sodium. A nylon monofilament with a silicone-beaded tip was inserted into the right internal carotid artery of the mice through the external carotid artery to occlude the origin of the middle cerebral artery. Reperfusion $(24 \mathrm{~h})$ was performed after $90 \mathrm{~min}$ of occlusion. Polyethylene catheters inserted into the right femoral artery were used for the measurement of blood pressure, and for the detection of arterial blood gases and glucose sampling. The body temperature of the mice during surgical procedures was maintained at $37^{\circ} \mathrm{C}\left( \pm 0.5^{\circ} \mathrm{C}\right)$ with the use of a heating pad.

Neurological deficits analysis. Neurological examination was performed after $24 \mathrm{~h}$ of ischemia/reperfusion in mice. Neurological deficits in mice ( $n=8 /$ group) were assessed using a standard 5-point scale as described previously (18). The scale was based on the following deficit criteria: 0 , no deficit; 1 , failure to fully extend left forepaw; 2 , circling to the left; 3 , falling to the left; 4 , unable to walk spontaneously or stroke-associated mortality. The examination was performed by an investigator that was blinded to the animal groupings.

Measurement of infarct size and volume. After neurological testing, mice were anesthetized with pentobarbital sodium $(50 \mathrm{mg} / \mathrm{kg})$ and were decapitated. Brains were collected from the rats ( $n=5 /$ group) and were sliced into five coronal sections (1 mm). The brain sections were stained with 2\% 2,3,5-triphenyltetrazolium chloride at $37^{\circ} \mathrm{C}$ for $30 \mathrm{~min}$ and were fixed in $4 \%$ paraformaldehyde. Imaging of the stained cerebral sections was performed and analyzed using the Image Pro-Plus analysis system version 6.3 (Media Cybernetics, Inc., Rockville, MD, USA). Infarct size was determined using the following equation: Corrected infarct volume $=$ contralateral hemisphere volume - (ipsilateral hemisphere volume - measured infarct volume). Infarct volume was presented as the percentage in the brain samples compared with the control. Infarct volume measurements were performed by an investigator that was blinded to the animal groupings.

Terminal deoxynucleotidyl transferase dUTP nick end labeling (TUNEL) apoptosis assay. The TUNEL assay was performed using the In Situ Cell Death Detection kit (Roche Diagnostics, Minneapolis, MN, USA) according to the manufacturer's protocol. After neurological testing, mice ( $n=3 /$ group) were anesthetized with pentobarbital sodium $(50 \mathrm{mg} / \mathrm{kg})$ and 
were decapitated. Paraffin-embedded sections were deparaffinized in xylene and rehydrated in a graded ethanol series to water. Excess water was removed from slides and sections were permeabilized with $20 \mu \mathrm{g} / \mathrm{ml}$ proteinase $\mathrm{K}$ (Gibco; Thermo Fisher Scientific, Inc.) prepared in $10 \mathrm{mM}$ Tris buffer (pH 7.5) containing $5 \mathrm{mM}$ EDTA. Sections were incubated at room temperature for $30 \mathrm{~min}$ and subsequently treated with $3 \%$ hydrogen peroxidase for $30 \mathrm{~min}$ and washed in PBS to quench endogenous peroxidases. Following equilibration, the sections were end labeled with digoxigenin-11-deoxyuridine triphosphate by incubation with the terminal deoxynucleotidyl transferase enzyme in buffer containing $50 \mathrm{mM}$ potassium acetate, $20 \mathrm{mM}$ Tris-acetate, $10 \mathrm{mM}$ magnesium acetate (pH 7.9) supplemented with $0.25 \mathrm{mM} \mathrm{CoCl} 2$ for $1 \mathrm{~h}$ at $37^{\circ} \mathrm{C}$ in a humidified chamber. Following treatment with stop-wash buffer, the sections were incubated with DAPI for $30 \mathrm{~min}$ and TUNEL-positive cells and double stained cells of different groups were observed randomly in the penumbra under a light microscope.

RNA isolation and reverse transcription-quantitative polymerase chain reaction ( $R T-q P C R)$. Tissue was homogenized at $4^{\circ} \mathrm{C}$ and total RNA was extracted from brain sections ( $n=3 /$ group) using TRIzol ${ }^{\circledR}$ reagent (Invitrogen; Thermo Fisher Scientific, Inc.) according to the manufacturer's protocol. Total RNA was quantified spectrophotometrically and $1 \mu \mathrm{g}$ RNA was reverse transcribed using SuperScript III kit (Invitrogen; Thermo Fisher Scientific, Inc.). Briefly, RNA was added to $0.5 \mathrm{mM}$ dNTPs, $200 \mathrm{ng}$ random hexamers, reaction buffer containing 5 mM DTT, 40 units RNAse A and 200 units reverse transcriptase, and was processed in a thermal cycler at $65^{\circ} \mathrm{C}$ for $30 \mathrm{~min}$. The obtained cDNA was used for differential PCR amplification of targeted genes in an ABI PRISM 7500 system (Applied Biosystems; Thermo Fisher Scientific, Inc.). Target amplification was performed using TaqMan minor groove binder probes labeled with fluorescein dye (Applied Biosystems; Thermo Fisher Scientific, Inc.) in a $20 \mu \mathrm{l}$ reaction mixture containing $2 \mu \mathrm{l} \mathrm{cDNA}$, ROX passive reference dyes and TaqMan Universal PCR mix (Applied Biosystems; Thermo Fisher Scientific, Inc.). The thermocycling conditions were as follows: $95^{\circ} \mathrm{C}$ for $5 \mathrm{~min}$; followed by 35 cycles of $95^{\circ} \mathrm{C}$ for $10 \mathrm{sec}, 60^{\circ} \mathrm{C}$ for $20 \mathrm{sec}$ and $72^{\circ} \mathrm{C}$ for $15 \mathrm{sec}$. The specific primer sets used were as follows: Parp1 (Entrez Gene ID, 25591; Rn00565018_m1) and caspase-3 (Casp3) (Entrez Gene ID, 25402; Rn00563902_m1) (Applied Biosystems; Thermo Fisher Scientific, Inc.). The human 18S rRNA was used as an internal control (Entrez Gene ID, 19791; NR_003278), and for normalization of the relative quantification of target gene expression. The relative quantification was performed using the $2^{-\Delta \Delta C q}$ method as previously described (19).

Neuroapoptotic mice and midazolam administration. Female BALB/c mice (age, 7 days; weight, 2.2-2.5 g) were used for analyzing neuroapoptosis due to their sensitivity to anesthetic agents, such as $\mathrm{GABA}_{\mathrm{A}}$ or N-methyl-D-aspartate agonists (14). The mice were housed at $22-24^{\circ} \mathrm{C}$ with humidity at $50-60 \%$ and a 12 -h light/dark cycle. Mice were allowed access to food and water ad libitum. The mice were randomly divided into four groups ( $\mathrm{n}=10 /$ group): Control group; ethanol group $(5 \mathrm{mg} / \mathrm{kg})$; ethanol + midazolam treatment group-1
(2 mg/kg); ethanol + midazolam treatment group-2 $(5 \mathrm{mg} / \mathrm{kg})$. Neuroapoptosis was induced in the brains of the mouse pups via administration of ethanol, which is a neurotoxic agent to the developing brain, according to a previously described method (20). Mice in the control group received normal saline (s.c.). The total volume of administered solutions was $<50 \mu 1$ per mouse. The body temperature of the mice was maintained at $37^{\circ} \mathrm{C}\left( \pm 0.5^{\circ} \mathrm{C}\right)$ with the use of a heating pad. Mice were initially administered midazolam for $6 \mathrm{~h}$, followed by a single injection of ethanol, and were then returned to normal conditions. A total of $6 \mathrm{~h}$ after ethanol administration, the mice were anesthetized with $2.5 \%$ isoflurane and decapitated, and the brains were extracted and fixed in paraformaldehyde.

Immunohistochemistry (IHC) and TUNEL staining for apoptosis. Paraffin-embedded tissues were prepared by standard method. Brain samples were extracted, washed with PBS then fixed in 4\% paraformaldehyde in PBS for $6 \mathrm{~h}$. Following fixation, tissues were rinsed with PBS to completely remove fixative. Tissues were subsequently dehydrated in graded alcohol and subjected to paraffin infiltration in molten paraffin wax at $65^{\circ} \mathrm{C}$ in blocks. The wax infiltrated tissues, embedded in blocks, were subjected to further procedure. Brain histology was studied in the paraffin-embedded sections ( $n=5 /$ group). Briefly, brain sections were deparaffinized and antigen retrieval was performed using Dako Target Retrieval Solution (Dako Denmark A/S, Glostrup, Denmark) according to the standard protocol. Tissue sections were washed with water and incubated with $3 \% \mathrm{H}_{2} \mathrm{O}_{2}$ for 5 min to block endogenous peroxidase. The sections were then incubated with anti-active caspase-3 (cat. no. 9661; Cell Signaling Technology, Inc.) diluted to 1:500 in blocking agent, for $30 \mathrm{~min}$ at room temperature. Subsequently, tissue sections were washed with TBST and incubated with HRP-labeled anti-rabbit secondary antibody (1:500; cat. no. E0432; Dako Denmark A/S) for 30 min at room temperature followed by visualization with 3,3'-diaminobenzidine chromogen (Dako Denmark A/S). Counterstaining was performed with hematoxylin, and caspase-3-positive staining was documented under a light microscope. The scoring of caspase-3-positive cells per $\mathrm{mm}^{2}$ brain section was performed by an investigator that was blinded to the animal groupings. The total number of caspase-3-positive cells was presented as a percentage of positive cells compared to the control group. TUNEL staining of the brain sections ( $n=5 /$ group) was conducted as aforementioned.

Statistical analyses. Experiments were repeated in triplicate. Data are presented as the mean \pm standard deviation and statistical differences among groups were calculated using Student's t-test or one-way analysis of variance followed by Tukey's post-hoc test. Neurological deficit was analyzed by Kruskal-Wallis test with Bonferroni correction. Statistical analyses were conducted using SPSS v.16.0 (SPSS, Inc., Chicago, IL, USA). $\mathrm{P}<0.05$ was considered to indicate a statistically significance difference.

\section{Results}

Effects of midazolam on oxidative stress-induced neuronal cell death. In order to investigate the effects of midazolam 

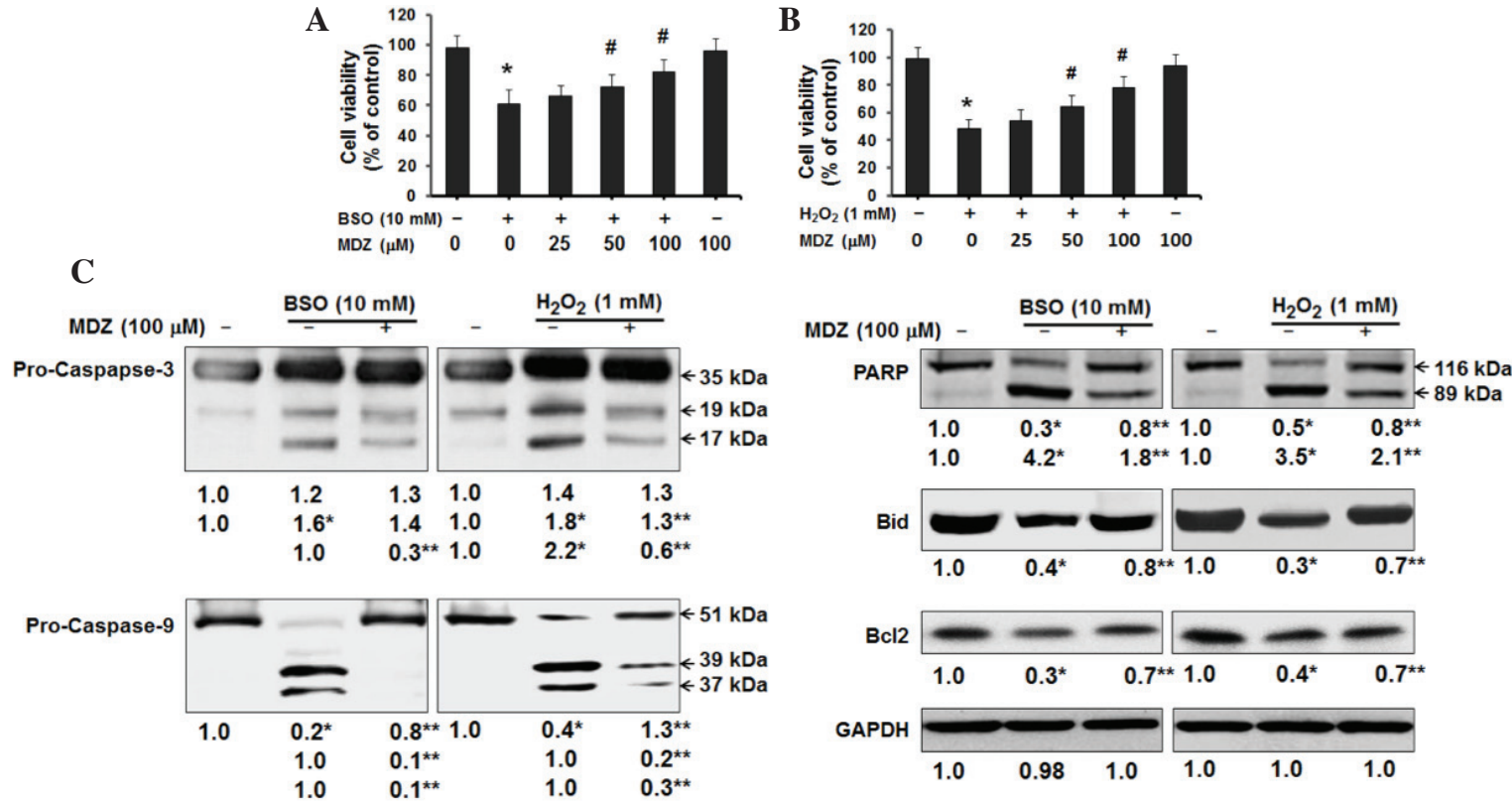

Figure 1. Effects of midazolam on proliferation of oxidative stress-induced cortical neuronal cells. Cells were treated with (A) $\mathrm{BSO}_{\text {or }}(\mathrm{B}) \mathrm{H}_{2} \mathrm{O}_{2}$ and the indicated concentrations of midazolam for $48 \mathrm{~h}$, and cell viability was analyzed by MTT assay. Viable cells are presented as a percentage of the control, and data are presented as the mean \pm standard deviation for 6 -wells per group. The whole experiment was repeated in triplicate. " $\mathrm{P}<0.05 \mathrm{vs}$. control group; ${ }^{~} \mathrm{P}<0.05$ vs. $\mathrm{BSO} / \mathrm{H}_{2} \mathrm{O}_{2}$ group. (C) Western blotting for apoptosis-associated proteins was performed and semi-quantified. " $\mathrm{P}<0.05$ vs. the control, ${ }^{* *} \mathrm{P}<0.05$ vs. $\mathrm{BSO} / \mathrm{H}_{2} \mathrm{O}_{2}$-treated cells. BSO, buthionine sulfoximine; $\mathrm{H}_{2} \mathrm{O}_{2}$, hydrogen peroxide; MDZ, midazolam; PARP, poly (ADP-ribose) polymerase; Bid, BH3 interacting-domain death agonist; Bcl2, B-cell lymphoma 2.
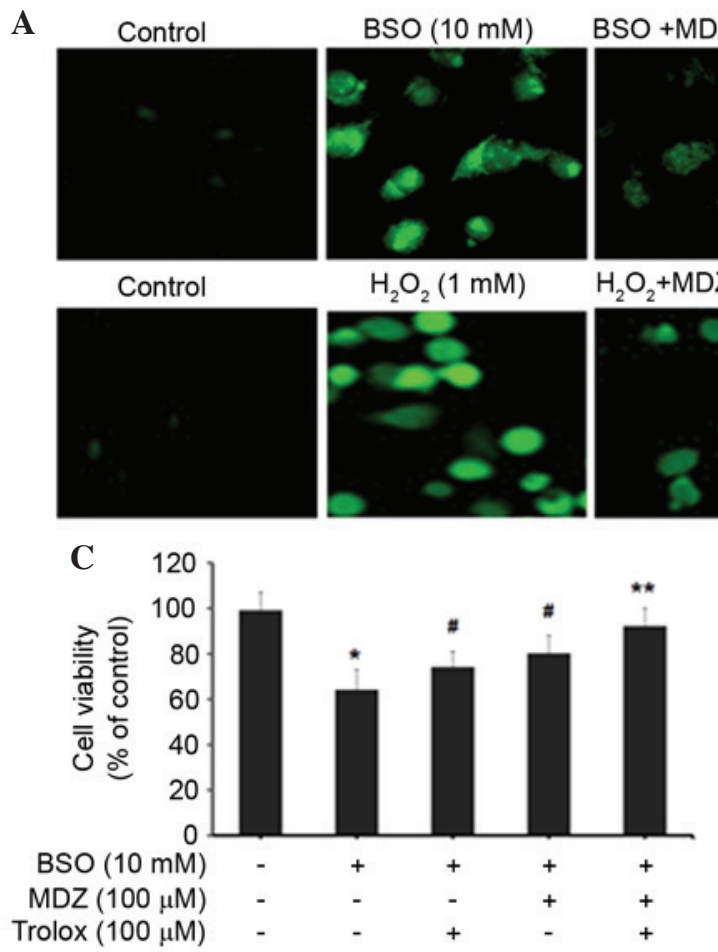

$\mathrm{BSO}+\mathrm{MDZ}(100 \mu \mathrm{M}) \quad$ B
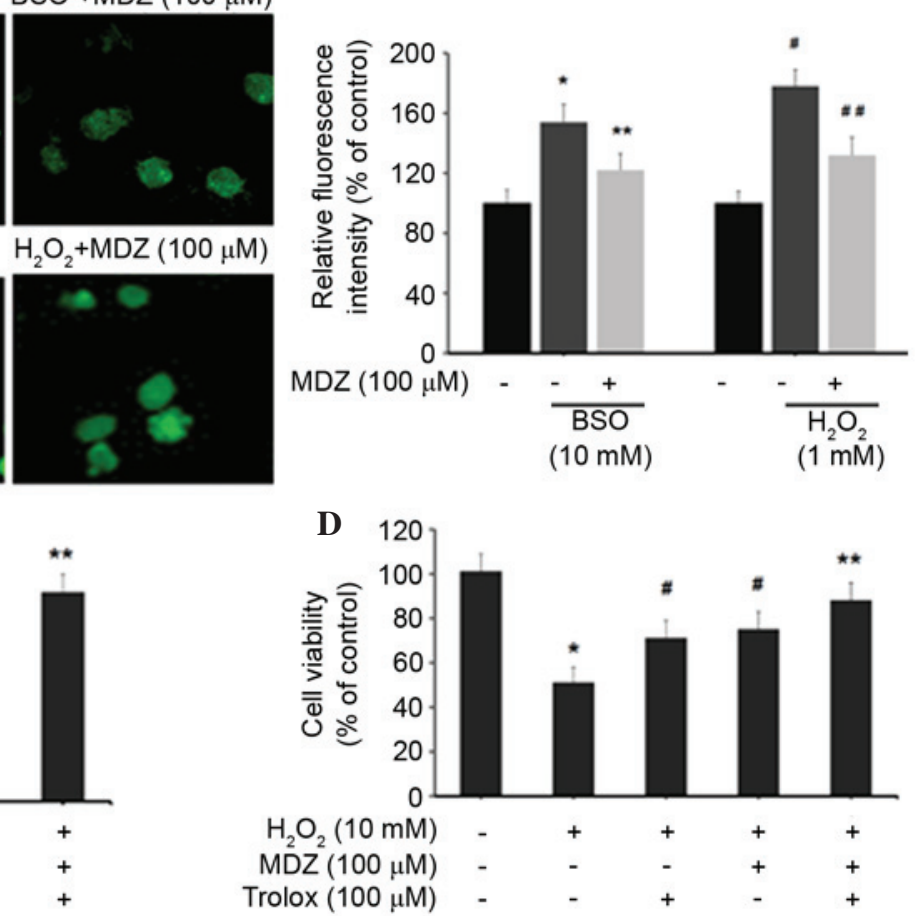

Figure 2. Effects of midazolam on intracellular ROS generation in oxidative stress-induced cortical neuronal cells. (A) ROS generation was measured using the $\mathrm{H}_{2}$ DCFDA assay. Cortical neuronal cells were treated with $\mathrm{BSO} / \mathrm{H}_{2} \mathrm{O}_{2}$ and midazolam for $24 \mathrm{~h}$. Cells were then incubated with $10 \mathrm{mM} \mathrm{H}_{2} \mathrm{DCFDA}$ and images were captured using laser scanning confocal microscopy. (B) 2',7'-dichlorofluorescein intensity was quantified and represented as relative fluorescence intensity (percentage of control). ${ }^{*} \mathrm{P}<0.05$ vs. the control, ${ }^{* *} \mathrm{P}<0.05$ vs. BSO, ${ }^{\#} \mathrm{P}<0.05$ vs. the control, ${ }^{\# \#} \mathrm{P}<0.05$ vs. $\mathrm{H}_{2} \mathrm{O}_{2}$. (C and D) Cells were treated with $\mathrm{BSO} / \mathrm{H}_{2} \mathrm{O}_{2}$ in combination with midazolam and trolox, and cell viability was assessed. Data are presented as the mean \pm standard deviation. ${ }^{*} \mathrm{P}<0.05$ vs. the control, ${ }^{\#} \mathrm{P}<0.05$ vs. $\mathrm{BSO} / \mathrm{H}_{2} \mathrm{O}_{2}$ ${ }^{* *} \mathrm{P} \geq 0.05$ vs. the control. BSO, buthionine sulfoximine; $\mathrm{H}_{2} \mathrm{O}_{2}$, hydrogen peroxide; MDZ, midazolam; $\mathrm{H}_{2}$ DCFDA, 2',7'-dichlorodihydrofluorescein diacetate.

on neuronal cell function and physiology, the present study induced oxidative stress in murine cortical neuronal cells.
Two oxidative stress inducers $\left(\mathrm{BSO}\right.$ and $\left.\mathrm{H}_{2} \mathrm{O}_{2}\right)$ were individually used to analyze the effects of midazolam. $\mathrm{BSO}$ is 

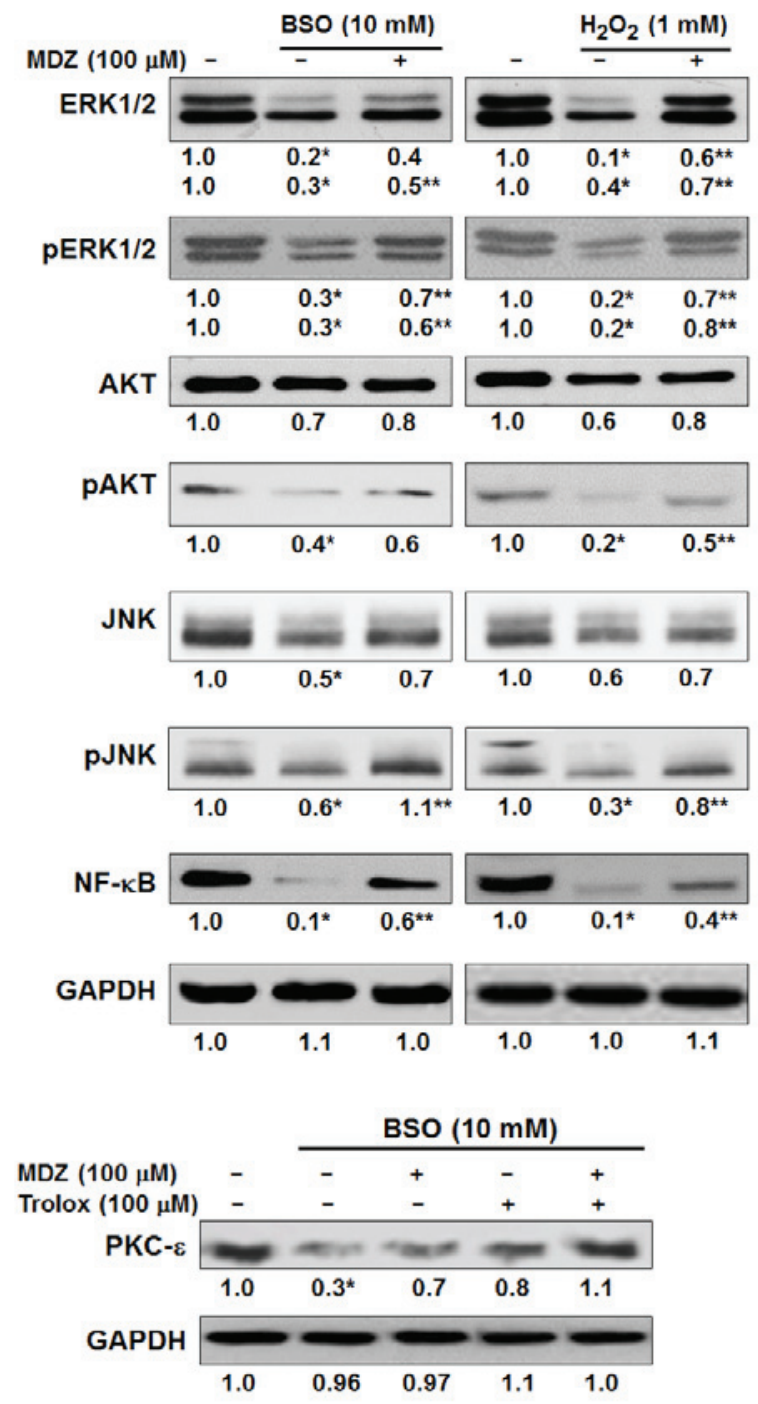

Figure 3. Effects of midazolam on cell survival signaling in oxidative stress-induced cortical neuronal cells. Cells were treated with the indicated reagents at the specified doses for $24 \mathrm{~h}$ and western blotting was performed and semi-quantified. ${ }^{*} \mathrm{P}<0.05$ vs. control; ${ }^{* *} \mathrm{P}<0.05$ vs. the $\mathrm{BSO} / \mathrm{H}_{2} \mathrm{O}_{2}$-treated cells. BSO, buthionine sulfoximine; $\mathrm{H}_{2} \mathrm{O}_{2}$, hydrogen peroxide; MDZ, midazolam; p, phosphorylated; ERK1/2, extracellular signal-regulated kinases $1 / 2$; JNK, c-Jun N-terminal kinases; NF- $\kappa B$, nuclear factor- $\kappa \mathrm{B}$; $\mathrm{PKC}-\varepsilon$, protein kinase $\mathrm{C}-\varepsilon$.

a sulfoximine compound that reduces glutathione levels by inhibiting $\gamma$-glutamylcysteine synthetase, which is the enzyme essential for the first step of glutathione synthesis. BSO induces generation of intracellular ROS and ultimately causes apoptosis (21). $\mathrm{H}_{2} \mathrm{O}_{2}$ is another inducer of intracellular ROS generation in neuronal cells (22). In the present study, primary cortical neuronal cell cultures were treated with $\mathrm{BSO}$ or $\mathrm{H}_{2} \mathrm{O}_{2}$ and were then treated with or without midazolam for $48 \mathrm{~h}$ prior to assessment of cell viability. The results of an MTT assay demonstrated that BSO $(10 \mathrm{mM})$ inhibited the growth of cortical neuronal cells to $61 \%$ compared with the control cells. Treatment of cells with midazolam increased cell growth in a dose-dependent manner; cells treated with $100 \mu \mathrm{M}$ midazolam exhibited $82 \%$ cell viability, as compared with the control cells (Fig. 1A). In cells treated with $\mathrm{H}_{2} \mathrm{O}_{2}, \mathrm{H}_{2} \mathrm{O}_{2}(1 \mathrm{mM})$ inhibited the growth of cortical neuronal cells to $48 \%$ compared with the control cells. Treatment of cells with midazolam increased cell growth in a dose-dependent manner; cells treated with $100 \mu \mathrm{M}$ midazolam exhibited $78 \%$ cell survival, as compared with the control cells (Fig. 1B). Midazolam (100 $\mu \mathrm{M})$ alone was found to be non-cytotoxic to cortical neuronal cells; cells treated with $100 \mu \mathrm{M}$ midazolam exhibited 94 and $96 \%$ cell viability compared with the control cells. The protective effects of midazolam in oxidative stress-induced cortical neuronal cells were further confirmed by western blotting of apoptosis-associated proteins (Fig. 1C). BSO treatment $(10 \mathrm{mM})$ resulted in activation of pro-caspase- 3 and cleavage of PARP. However, $100 \mu \mathrm{M}$ midazolam treatment resulted in reduced levels of activated caspase-3 and cleaved-PARP (Fig. 1C). Furthermore, BSO induced truncation-activation of Bid and reduced $\mathrm{Bcl} 2$ expression; these effects were reversed by treatment with midazolam (Fig. 1C). Similarly, $\mathrm{H}_{2} \mathrm{O}_{2}$ treatment $(1 \mathrm{mM})$ resulted in activation of pro-caspase-3, cleavage of PARP, truncation-activation of Bid and reduced expression of $\mathrm{Bcl} 2$. Conversely, midazolam treatment attenuated the effects of $\mathrm{H}_{2} \mathrm{O}_{2}$ (Fig. 1C). Activation of pro-caspase-9 in both oxidative stress conditions indicates the putative activation of the mitochondrial intrinsic apoptosis pathway, which was suppressed following exposure to midazolam. These results suggest that $\mathrm{BSO}$ and $\mathrm{H}_{2} \mathrm{O}_{2}$ may inhibit the proliferation of cortical neuronal cells by inducing apoptosis, and that the treatment of cells with midazolam may recover cell growth.

Midazolam suppresses generation of intracellular ROS in neuronal cells. The effects of midazolam on intracellular ROS levels were determined by $\mathrm{H}_{2}$ DCFDA assay. Treatment of cortical neuronal cells with $\mathrm{BSO}(10 \mathrm{mM})$ and $\mathrm{H}_{2} \mathrm{O}_{2}(1 \mathrm{mM})$ resulted in increased production of intracellular ROS, as demonstrated by increased cellular fluorescence intensity (Fig. 2A). Quantification of intracellular ROS levels was determined by measuring DCF intensity. Cortical neuronal cells treated with BSO $(10 \mathrm{mM})$ exhibited increased DCF intensity $(154 \pm 12 \%)$ compared with the control cells (100\%). BSO-induced DCF intensity was subsequently inhibited following treatment with $100 \mu \mathrm{M}$ midazolam $(122 \pm 11 \%)$. Similarly, $\mathrm{H}_{2} \mathrm{O}_{2}(1 \mathrm{mM})$ treatment increased DCF intensity to $178 \pm 11 \%$ compared with the control group; however, DCF intensity was subsequently inhibited following treatment with $100 \mu \mathrm{M}$ midazolam $(132 \pm 12 \%)$ (Fig. 2B). These results indicate that midazolam has the ability to suppress intracellular ROS accumulation, and may possess free radical scavenging activities, thus preventing neuronal cell death. Furthermore, the present study detected the viability of oxidative stress-induced cortical neuronal cells following treatment with midazolam in combination with trolox. Trolox (6-hydroxy-2,5,7,8-tetramethylchroman-2-carboxylic acid) is a well-known antioxidant that suppresses intracellular ROS generation. In the BSO-treated groups, cell viability percentages for each group were as follows: BSO $(10 \mathrm{mM}), 64 \%$; trolox $(100 \mu \mathrm{M}), 74 \%$; and midazolam $(100 \mu \mathrm{M}), 80 \%$ (Fig. 2C). The combination of trolox and midazolam exerted a synergistic effect; cell viability was $92 \%$ compared with the control cells (100\%). In the $\mathrm{H}_{2} \mathrm{O}_{2}$-treated groups, the cell viability percentages for each group were as follows: $\mathrm{H}_{2} \mathrm{O}_{2}(1 \mathrm{mM}), 51 \%$; trolox $(100 \mu \mathrm{M}), 71 \%$; and midazolam $(100 \mu \mathrm{M}), 75 \%$ (Fig. 2D). The combination of trolox and midazolam exerted a synergistic effect; cell viability was $88 \%$ compared with the control cells. Collectively these data indicate that $\mathrm{BSO}$ and $\mathrm{H}_{2} \mathrm{O}_{2}$ induce 
Table I. Neurological deficit scoring following ischemia/reperfusion ( $\mathrm{n}=8 /$ group).

Neurological deficit scores

\begin{tabular}{llllllr}
\cline { 2 - 5 } Group & 0 & 1 & 2 & 3 & 4 & Median (range) \\
\hline Control & 8 & 0 & 0 & 0 & 0 & 0 \\
MCAO & 0 & 1 & 2 & 4 & 1 & $1(1-4)$ \\
MCAO + MDZ (2 mg/kg) & 1 & 3 & 2 & 2 & 0 & $2(0-3)^{\mathrm{a}}$ \\
MCAO + MDZ (5 mg/kg) & 3 & 4 & 1 & 0 & 0 & $4(0-4)^{\mathrm{b}}$ \\
\hline
\end{tabular}

MCAO, middle cerebral artery occlusion; MDZ, midazolam. ${ }^{\mathrm{a}} \mathrm{P}<0.05$ and ${ }^{\mathrm{b}} \mathrm{P}<0.03$ vs. MCAO group.

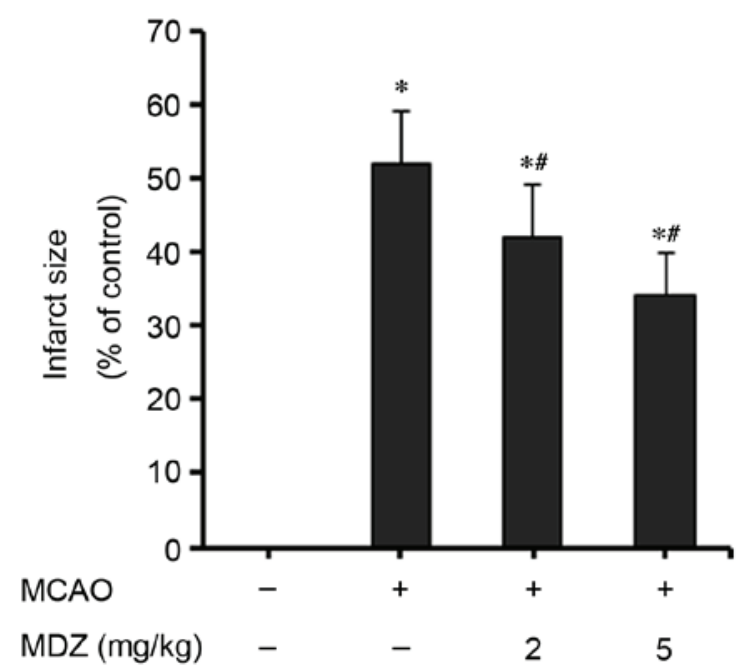

Figure 4. Effects of midazolam on infarct size in MCAO mice. Mice brains ( $n=5 /$ group) were processed and imaging of stained cerebral sections was performed and analyzed using the Image Pro-Plus analysis system. Infarct volume was presented as the percentage in the brain samples compared with the control $(0 \%)$. Data are presented as the mean \pm standard deviation ${ }^{*} \mathrm{P}<0.05$ vs. the control; ${ }^{\#} \mathrm{P}<0.05$ vs. MCAO. MCAO, middle cerebral artery occlusion; MDZ, midazolam.

oxidative stress in cortical neuronal cells resulting in growth inhibition. The reversal of $\mathrm{BSO}$ and $\mathrm{H}_{2} \mathrm{O}_{2}$-induced effects by midazolam indicates its ROS inhibitory properties.

Midazolam enhances survival in cortical neuronal cells under oxidative stress. The present study aimed to elucidate the molecular mechanisms underlying the protective effects of midazolam on oxidative stress-induced apoptosis in cortical neuronal cells. Western blotting demonstrated that treatment with $\mathrm{BSO}$ and $\mathrm{H}_{2} \mathrm{O}_{2}$ suppressed the expression levels of cell survival-associated proteins in cortical neuronal cells (Fig. 3). BSO $(10 \mathrm{mM})$ and $\mathrm{H}_{2} \mathrm{O}_{2}(1 \mathrm{mM})$ suppressed the protein expression levels of ERK1/2, pERK1/2, AKT and pAKT. In $\mathrm{BSO}$ and $\mathrm{H}_{2} \mathrm{O}_{2}$ treatment groups, midazolam $(100 \mu \mathrm{M})$ recovered the protein expression levels of ERK, pERK, AKT and pAKT. Suppression of pERK and pAKT by BSO and $\mathrm{H}_{2} \mathrm{O}_{2}$ was comparatively higher compared with the suppression of their native forms. In addition, $\mathrm{BSO}$ and $\mathrm{H}_{2} \mathrm{O}_{2}$ suppressed activation of JNK and pJNK proteins, which was reversed following treatment with midazolam $(100 \mu \mathrm{M})$. Suppression of JNK and pJNK activation by BSO and $\mathrm{H}_{2} \mathrm{O}_{2}$ is directly associated with the suppression of major cell survival signals in cortical neuronal cells. Furthermore, the recovery of JNK and pJNK expression by midazolam indicates its protective effects against $\mathrm{BSO}$ and $\mathrm{H}_{2} \mathrm{O}_{2}$. $\mathrm{BSO}$ and $\mathrm{H}_{2} \mathrm{O}_{2}$ also suppressed the expression of $\mathrm{NF}-\kappa \mathrm{B}$, which is transcriptional regulator of the Bcl-2 family that contains pro- and anti-apoptosis genes. This family of genes also regulates cell survival signaling. Thus, an increase in $\mathrm{NF}-\kappa \mathrm{B}$ by midazolam results in an increase in cell survival, suggesting reduced apoptosis. Midazolam was shown to elevate the levels of $\mathrm{NF}-\kappa \mathrm{B}$, which were inhibited by $\mathrm{BSO}$ and $\mathrm{H}_{2} \mathrm{O}_{2}$ (Fig. 3). $\mathrm{NF}-\kappa \mathrm{B}$ modulation is also associated with ERK and AKT signaling, as corroborated by the present results. These results suggest that the protective effects of midazolam on oxidative stress-induced cortical neuronal cells are mediated via modulation of JNK and $\mathrm{NF}-\kappa \mathrm{B}$ signaling. BSO has been reported to act through inhibition of PKC cell signaling pathway proteins, particularly PKC- $\varepsilon$ (21). Therefore, the present study analyzed the protein expression levels of PKC- $\varepsilon$ in BSO and midazolam-treated cortical neuronal cells by western blotting. As hypothesized, BSO (10 mM) inhibited the protein expression levels of PKC- $\varepsilon$, whereas midazolam $(100 \mu \mathrm{M})$ treatment moderately recovered PKC- $\varepsilon$ expression. In addition, trolox suppressed the effects of BSO by elevating PKC- $\varepsilon$ levels. The combination of trolox and midazolam exerted a synergistic effect on the recovery of PKC- $\varepsilon$ protein levels, which were inhibited by BSO (Fig. 3). These results provide information regarding the mechanism underlying midazolam-induced suppression of oxidative stress in cortical neuronal cells.

Effects of midazolam on neuronal deficit and infarct volume in MCAO mice. In order to investigate the effects of midazolam on stress and ischemia, MCAO mice were used. Proximal occlusion of the middle cerebral artery is one of the most frequently used experimental models of stroke. The MCAO model is among the most common models of ischemic stroke and stress in the developing brain (17). MCAO mice are characterized by neuronal deficit, neuronal degeneration and cell death. In the present study, neuronal deficits in mice were evaluated $24 \mathrm{~h}$ following transient MCAO reperfusion (Table I). The results demonstrate that transient MCAO reperfusion induced severe neuronal deficits in mice; with $50 \%$ of mice classified as grade 3 and $12.5 \%$ of mice classified as grade 4 , as compared with the control group. Midazolam post-conditioning in MCAO mice improved the neurological 
A

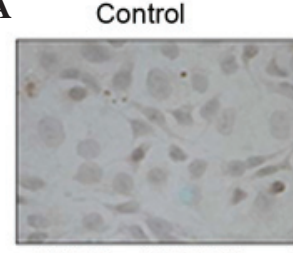

$\mathrm{MCAO}+\mathrm{MDZ}(2 \mathrm{mg})$

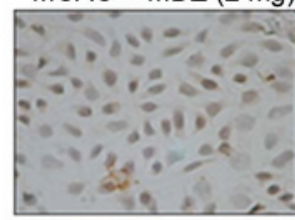

C

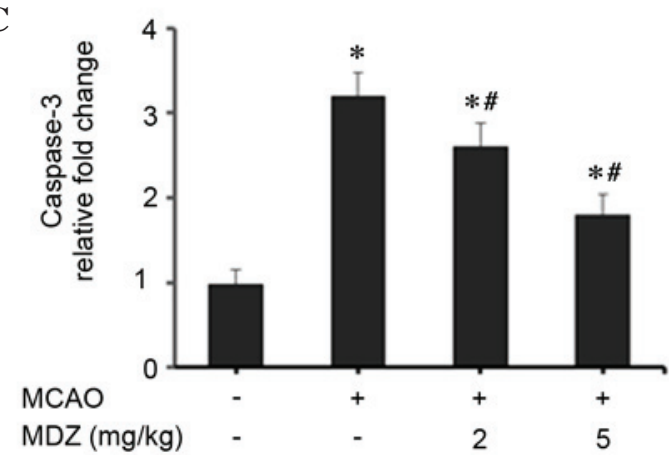

B

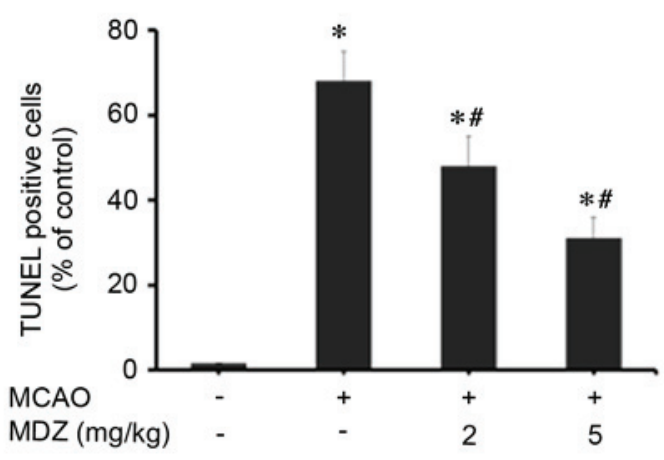

D

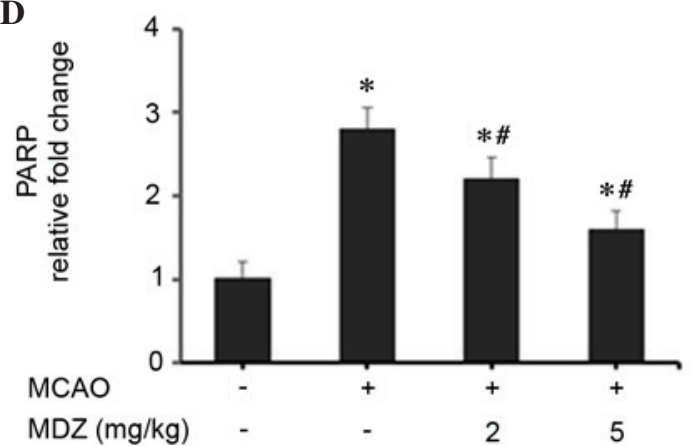

Figure 5. Effects of midazolam on neuroapoptosis in MCAO mice. (A) TUNEL assay was performed using In Situ Cell Death Detection kit. Brain sections ( $n=3$ /group) were processed for TUNEL staining, and cells were observed under a light microscope. Magnification, x40. (B) Quantitative estimation of TUNEL-positive cells fluorescence intensity is presented as a percentage of the control. Expression levels of (C) caspase-3 and (D) PARP genes were quantified by quantitative polymerase chain reaction ( $\mathrm{n}=3$ /group). Data are presented as the mean \pm standard deviation. ${ }^{*} \mathrm{P}<0.05 \mathrm{vs}$. the control; ${ }^{\sharp} \mathrm{P}<0.05 \mathrm{vs}$. MCAO. MCAO, middle cerebral artery occlusion; MDZ, midazolam; TUNEL, terminal deoxynucleotidyl transferase dUTP nick end labeling; PARP, poly (ADP-ribose) polymerase.

outcomes in a dose-dependent manner. Neuronal deficits in MCAO mice were improved following treatment with $2 \mathrm{mg} / \mathrm{kg}$ midazolam, with a median value of $2(\mathrm{P}<0.042)$ and with $5 \mathrm{mg} / \mathrm{kg}$ midazolam with a median value of $4(\mathrm{P}<0.028)$, as compared with the MCAO group (median value of 1 ). These results indicate that midazolam may exert protective effects against neuronal deficit and degeneration in mice with transient intraluminal occlusion. In addition, the present study examined the effects of midazolam on infarct size in MCAO mice. Brain sections were analyzed to determine the percentage of infarct area in the whole brain, and the results were presented as a percentage of the control (Fig. 4). Mice in the MCAO group exhibited extensive infarction (52 $\pm 7 \%)$ compared with the control group. Conversely, midazolam post-conditioning in MCAO mice significantly reduced infarct volume in a dose-dependent manner. Treatment of MCAO mice with 2 or $5 \mathrm{mg} / \mathrm{kg}$ midazolam reduced infarct size to $42 \pm 7 \%$ $(\mathrm{P}<0.05)$ and $34 \pm 6 \%(\mathrm{P}<0.03)$, respectively, as compared with the control group. These data suggest that midazolam exerts protective effects on $\mathrm{MCAO}$-induced brain infarction in mice.

Midazolam suppresses neuronal apoptosis in MCAO mice. The present study examined the effects of midazolam on neuronal apoptosis in MCAO mice using TUNEL staining and RT-qPCR of apoptosis-associated genes (Fig. 5). Transient MCAO and reperfusion increased cellular apoptosis in the brain cortex compared with in the control group; however, apoptosis was markedly suppressed following treatment with midazolam in a dose-dependent manner (Fig. 5A). The number of cells stained for apoptotic bodies was markedly increased in the MCAO group compared with in the control group. Midazolam-treated MCAO mice exhibited a reduction in the number of apoptotic cells compared with the MCAO group. As presented in Fig. 5B, quantitative scoring of TUNEL-positive cells was conducted; a high percentage of TUNEL-positive apoptotic cells was detected in the MCAO group (68+7\%). However, treatment of MCAO mice with 2 or $5 \mathrm{mg} / \mathrm{kg}$ midazolam reduced the percentage of TUNEL-positive apoptotic cells to $48 \pm 7 \%(\mathrm{P}<0.04)$ and $31 \pm 5 \%(\mathrm{P}<0.03)$, respectively. These findings emphasize the anti-apoptotic properties of midazolam in MCAO mice. The effects of midazolam on apoptosis in MCAO mice were further confirmed by RT-qPCR analysis of apoptosis-associated genes (caspase-3 and PARP). The mitochondrial intrinsic apoptosis pathway induces cell death via activation of the executioner caspase-3, followed by cleavage of the nuclear substrate PARP. In MCAO mice, the expression levels of caspase-3 and PARP were increased 3.2- and 2.8-fold, respectively, as compared with in the control group (Fig. 5C and D). The expression levels of caspase-3 and PARP were dose-dependently suppressed following treatment of MCAO mice with midazolam. Treatment with 2 or $5 \mathrm{mg} / \mathrm{kg}$ midazolam reduced the expression levels of caspase-3 to 2.6and 1.8-fold, respectively, as compared with the control group (Fig. 5C). Similarly, treatment with 2 or $5 \mathrm{mg} / \mathrm{kg}$ midazolam reduced the expression levels of PARP to 2.2- and 1.6-fold, respectively, compared with the control group (Fig. 5D). These 
A

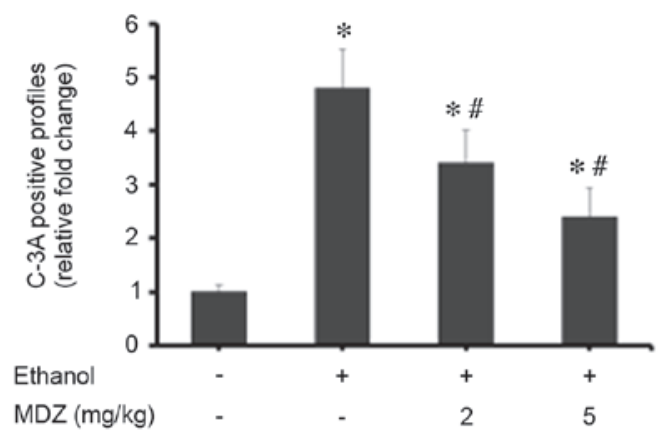

B

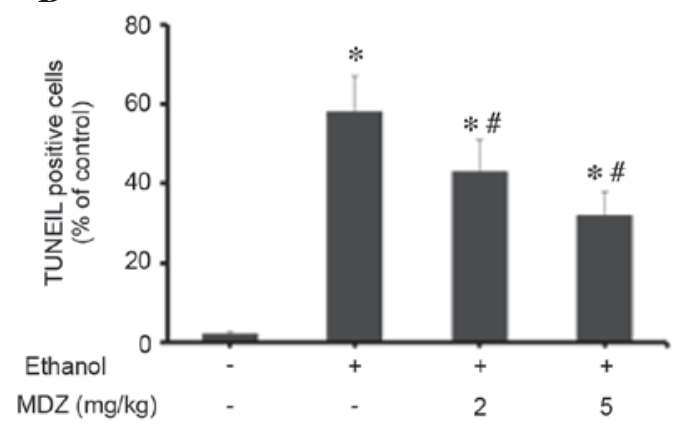

Figure 6. Effects of midazolam on ethanol-induced neuroapoptosis in mice. (A) Immunohistochemical analysis of brain sections ( $n=5 /$ group) was performed using anti-C-3A and was visualized using 3,3'-diaminobenzidine chromogen. The C-3A positive staining was documented under a light microscope and scoring of C-3A-positive cells per $\mathrm{mm}^{2}$ brain sections was performed. The total number of C-3A-positive cells was presented as the percentage of positive cells compared to the control group. (B) TUNEL staining of brain sections ( $\mathrm{n}=5 /$ group) was performed and analyzed. Data are presented as the mean \pm standard deviation. ${ }^{*} \mathrm{P}<0.05$ vs. control group, ${ }^{\#} \mathrm{P}<0.05$ vs. the MCAO group. MDZ, midazolam; C-3A, active caspase-3; TUNEL, terminal deoxynucleotidyl transferase dUTP nick end labeling.

findings were statistically significant when compared with the control group. Collectively, these data suggest that the protective effects of midazolam are attributed to its anti-apoptotic activities in MCAO mice.

Effects of midazolam on ethanol-induced neuronal apoptosis in mice. Ethanol exposure to infant rodents during neuronal development, particularly rapid synaptogenesis, can induce extensive neuronal apoptosis and degeneration (20). In the present study, the effects of midazolam on a mouse model of ethanol-induced neurodegeneration and apoptosis were assessed by activated caspase-3 IHC and TUNEL staining. The quantitative estimations of apoptosis were recorded and presented as a percentage of the control (Fig. 6). Quantification of the IHC results indicate that ethanol induced severe apoptosis in the brains, as demonstrated by the increased number of caspase-3-positive cells compared with the control group. Ethanol-induced a 4.8-fold increase in caspase-3-positive cells compared with the control (Fig. 5A). Conversely, treatment with midazolam resulted in a dose-dependent suppression in caspase-3-positive cells; treatment with 2 or $5 \mathrm{mg} / \mathrm{kg}$ midazolam suppressed the number of caspase-3-positive cells to 3.4- and 2.4-fold, respectively, as compared with the control group (Fig. 6A). The effects of midazolam on ethanol-induced neurodegeneration and apoptosis were further confirmed by TUNEL staining of the brain cortex. TUNEL staining of apoptotic cells was recorded as a percentage of the control (Fig. 6B). Exposure of mice to ethanol resulted in a marked increase in the percentage of TUNEL-positive cells (58 $\pm 9 \%$ ) compared with the control group. Treatment of ethanol-exposed mice with midazolam resulted in a dose-dependent suppression in TUNEL staining. Treatment with 2 or $5 \mathrm{mg} / \mathrm{kg}$ midazolam suppressed the ratio of TUNEL-positive cells to 43 and 32\%, respectively, as compared with the control group (Fig. 6B). These data indicate that midazolam protects the developing mouse brain from ethanol-induced neurodegeneration and apoptosis.

\section{Discussion}

Anesthetic and anticonvulsant agents are commonly used to induce sedation during clinical and surgical procedures. Although several such agents have been shown to induce neuronal degeneration, cytotoxicity and dysfunction, some have been reported to exert protective properties. The present study demonstrated that the commonly used anesthetic midazolam exerts protective effects on neuronal cells and the developing brain under physiological and oxidative stress conditions. Transient occlusion-induced apoptotic neuronal degeneration and ethanol-induced neuroapoptosis in the murine brain was reversed following treatment with midazolam. Furthermore, midazolam recovered oxidative stress-inhibited cortical neuronal cell growth via suppression of ROS, and modulation of JNK-ERK and NF-kB signaling pathways.

Ischemia/reperfusion in the developing brain may induce severe neurological damage, which may trigger a complex series of biochemical events resulting in structural and functional deficits in the nervous system. Transient global ischemia initiates intricate neuronal cell death processes following ischemic insult, particularly in developing brains. Anesthetics are used for their sedative properties; however, contradictory neurocytotoxic and neuroprotective properties have been reported in various in vitro and in vivo systems $(1,2,11,23,24)$. Recently, propofol was demonstrated to exert neuroprotective effects in hypoxia-induced hippocampal neuronal injury; it improved alterations in neuronal structure and decreased the release of amino acid neurotransmitters in hypoxic brains (25). Furthermore, propofol exerted neuroprotective effects in brain ischemia/reperfusion injury via the induction of heme oxygenase-1 expression (26). Propofol has also been reported to attenuate activation of caspase-3 in the cortex and hippocampus of mice, and may improve cognitive function, possibly through $\mathrm{GABA}_{\mathrm{A}}$ receptor action (27). In addition, isoflurane and midazolam have been demonstrated to be protective against neuronal degeneration and apoptosis (2). Another protective mechanism in neuronal cells is mediated by the suppression of oxidative stress-induced ROS. The natural polyphenol quercetin has been demonstrated to protect neuronal cells from oxidative stress-induced apoptosis by suppressing ROS accumulation and activation of the JNK, ERK1/2 and Akt signaling pathways (28). Resveratrol and quercetin also exert protective effects against oxidative stress-induced apoptotic cell death in dopaminergic neurons by suppressing ROS and modulating apoptotic markers (29). Therefore, clinical and therapeutic interventions that suppress 
oxidative stress may effectively protect against neuronal damage and neuroapoptosis.

The present study investigated the effects of midazolam, a rapidly acting intravenous hypnotic agent, on neuronal apoptosis and neurodegeneration. The results suggested that midazolam may improve neurological outcome in animal models of cerebral ischemia and neuroapoptosis. The neuroprotective effects of midazolam were comprehensively characterized in cortical neuronal cells, and in murine models of MCAO ischemia/reperfusion injury and ethanol-induced neuroapoptosis. BSO $(10 \mathrm{mM})$ and $\mathrm{H}_{2} \mathrm{O}_{2}(1 \mathrm{mM})$ were used to induce oxidative stress in primary cortical neuronal cells prepared from the developing mouse brain. $\mathrm{BSO}$ and $\mathrm{H}_{2} \mathrm{O}_{2}$ suppressed the proliferation of neuronal cells, whereas reduced cell proliferation was recovered following treatment with midazolam (Fig. 1A and B). In addition, in neuronal cells, BSO and $\mathrm{H}_{2} \mathrm{O}_{2}$ activated caspase- 3 and caspase-9, followed by cleavage of PARP, and activation of $\mathrm{Bid}$ and $\mathrm{Bcl} 2$, thus indicating activation of the mitochondrial intrinsic apoptosis pathway (Fig. 1C). Exposure to $\mathrm{BSO}$ and $\mathrm{H}_{2} \mathrm{O}_{2}$ increased the intracellular redox status of cortical neuronal cells, as assessed by DCF fluorescence intensity. Conversely, treatment of oxidative stress-induced cortical neuronal cells with midazolam resulted in reduced DCF intensity, and thus reduced levels of intracellular ROS (Fig. 2A and B). The ROS-lowering effects of midazolam were further confirmed by co-treatment of cells with midazolam and the known antioxidant agent, trolox. The combination of trolox and midazolam more effectively reduced ROS levels and elevated proliferation of neuronal cells, which was inhibited by BSO and $\mathrm{H}_{2} \mathrm{O}_{2}$ (Fig. 2C and D). In addition, a previous study demonstrated that midazolam exerts ROS-suppressing and cell survival-modulating activity in neuroblastoma cells (30).

Oxidative stress-induced neuronal damage is predominantly associated with activation of apoptotic cell death pathways, with strong implications for JNK and ERK1/2 signaling $(31,32)$. ERK $1 / 2$ is an important member of the mitogen-activated protein kinase (MAPK) family, which controls a broad range of cellular activities and physiological processes. ERK1/2 activation promotes cell survival and prevents against oxidative stress. JNKs also belong to the MAPK family and they regulate proliferation and differentiation functions in the cell. Whether the JNK activation leads to cell proliferation or apoptosis is dependent on the stimuli and the cell-type involved in such activation $(30,31)$. Previous reports have associated the mitogen-activated protein kinase signaling cascades (ERK1/2 and JNK) with oxidative stress-induced neuronal death $(28,31,32)$; similarly, the present study demonstrated that $\mathrm{BSO}$ and $\mathrm{H}_{2} \mathrm{O}_{2}$ reduced protein levels of JNK, pJNK, ERK and pERK in cortical neuronal cells (Fig. 3). Furthermore, midazolam was able to activate JNK-ERK and NF- $\kappa \mathrm{B}$ signaling pathways in oxidative stress-induced cortical neuronal cells (Fig. 3). Activation of the NF- $\kappa$ B pathway augments cell survival signaling via activation of ERK1/2-AKT signaling, inactivation of proapoptotic proteins (Bid and $\mathrm{Bcl} 2$-associated $\mathrm{X}$ protein) and upregulation of anti-apoptotic proteins (Bcl2 and Bcl-extra large) (33). In addition, midazolam induced PKC- $\varepsilon$ activation in cortical neuronal cells, which correlates with the suppression of ROS generation and apoptosis activation (Fig. 3). A previous study revealed that $\mathrm{BSO}$-induced $\mathrm{ROS}$ generation and neuronal cell death is mechanistically mediated by suppression of PKC- $\varepsilon$, and trolox may inhibit ROS elevation in BSO-treated cortical cells (21). Therefore, these results demonstrated that midazolam may exert protective effects against oxidative stress in neuronal cells via activation of JNK-ERK and NF- $\kappa \mathrm{B}$ signaling pathways, and elevation of PKC- $\varepsilon$, particularly in BSO-treated neuronal cells.

In the present study, the effects of midazolam were assessed in vivo in murine models of transient intraluminal occlusion and ethanol-induced neuroapoptosis. MCAO is a model of ischemic stroke and stress, and MCAO mice are characterized by neuronal deficit, neuronal degeneration and cell death. Midazolam post-conditioning resulted in improved neurological outcomes, reduced neuronal deficits and infarct size, and reduced apoptosis (Table I; Figs. 4 and 5). Midazolam infusion at the onset of reperfusion decreased infarct volume and cell apoptosis, and improved neurological deficits, thus indicating the protective histological properties of midazolam. In addition, midazolam reduced apoptotic TUNEL staining in MCAO mice, and reduced the expression levels of caspase- 3 and PARP. Exposure of ethanol to neonatal mice during brain development can induce severe neuronal apoptosis and degeneration (19). Treatment of ethanol-treated mice with midazolam suppressed the number of apoptotic cells in the brain sections (Fig. 6). Midazolam suppressed the elevated levels of activated caspase-3 IHC staining and TUNEL staining in the brain sections.

In conclusion, the present study emphasized the effectiveness of midazolam against oxidative stress in neuronal cells in vitro and in vivo. The results also emphasized the clinical implications of midazolam as an anesthetic that reduces pain during clinical and surgical procedures, which also offers protection against neurodegenerative side effects. Midazolam inhibited the generation of ROS and neuroapoptosis in oxidative stress-induced cortical neuronal cells. Furthermore, midazolam post-conditioning in MCAO mice improved neuronal physiology, reduced neuronal deficits, and decreased infarct size via suppression of ROS and inhibition of apoptosis. Midazolam also suppressed apoptosis in ethanol-treated neonatal mice brains. However, the dose and duration of anesthetic treatment remain important considerations for neuronal cell growth and death. The protective effects of midazolam are not solely dependent on apoptotic suppression, and activation of the JNK-ERK cell survival signaling pathway is additive to the effects of midazolam. The results of the present study advocate the safe and protective application of midazolam as a neuroprotective anesthetic agent.

\section{References}

1. So EC, Chang YT, Hsing CH, Poon PW, Leu SF and Huang BM: The effect of midazolam on mouse Leydig cell steroidogenesis and apoptosis. Toxicol Lett 192: 169-178, 2010.

2. Jevtovic-Todorovic V, Hartman RE, Izumi Y, Benshoff ND, Dikranian K, Zorumski CF, Olney JW and Wozniak DF: Early exposure to common anesthetic agents causes widespread neurodegeneration in the developing rat brain and persistent learning deficits. J Neurosci 23: 876-882, 2003.

3. Head BP, Patel HH, Niesman IR, Drummond JC, Roth DM and Patel PM: Inhibition of 775 neurotrophin receptor attenuates isoflurane-mediated neuronal apoptosis in the neonatal central nervous system. Anesthesiology 110: 813-825, 2009. 
4. Vutskits L, Gascon E, Tassonyi E and Kiss JZ: Clinically relevant concentrations of propofol but not midazolam alter in vitro dendritic development of isolated gamma-aminobutyric acid-positive interneurons. Anesthesiology 102: 970-976, 2005.

5. Stratmann G, Sall JW, May LD, Bell JS, Magnusson KR, Rau V, Visrodia KH, Alvi RS, Ku B, Lee MT and Dai R: Isoflurane differentially affects neurogenesis and long-term neurocognitive function in 60-day-old and 7-day-old rats. Anesthesiology 110: 834-848, 2009

6. Walker SM, Westin BD, Deumens R, Grafe M and Yaksh TL: Effects of intrathecal ketamine in the neonatal rat: Evaluation of apoptosis and long-term functional outcome. Anesthesiology 113 147-159, 2010.

7. Briner A, De Roo M, Dayer A, Muller D, Habre W and Vutskits L: Volatile anesthetics rapidly increase dendritic spine density in the rat medial prefrontal cortex during synaptogenesis. Anesthesiology 112: 546-556, 2010.

8. De Roo M, Klauser P, Briner A, Nikonenko I, Mendez P, Dayer A, Kiss JZ, Muller D and Vutskits L: Anesthetics rapidly promote synaptogenesis during a critical period of brain development. PLoS One 4: e7043, 2009.

9. Yahalom B, Athiraman U, Soriano SG, Zurakowski D, Carpino EA, Corfas G and Berde CB: Spinal anesthesia in infant rats: Development of a model and assessment of neurologic outcomes. Anesthesiology 114: 1325-1335, 2011

10. Scallet AC, Schmued LC, Slikker W Jr, Grunberg N, Faustino PJ, Davis H, Lester D, Pine PS, Sistare F and Hanig JP: Developmental neurotoxicity of ketamine: Morphometric confirmation, exposure parameters, and multiple fluorescent labeling of apoptotic neurons. Toxicol Sci 81: 364-370, 2004.

11. Abdel-Wahab AF and Al-Harizy WM: Propofol protects against ischemia/reperfusion injury associated with reduced apoptosis in rat liver. ISRN Anesthesiology 2013, Article ID 517478, 8 pages, 2013.

12. Arai Y, Kondo T, Tanabe K, Zhao QL, Li FJ, Ogawa R, Li M and Kasuya M: Enhancement of hyperthermia-induced apoptosis by local anesthetics on human histiocytic lymphoma U937 cells. J Biol Chem 277: 18986-18993, 2002.

13. Mishra SK, Kang JH, Lee CW, Oh SH, Ryu JS, Bae YS and Kim HM: Midazolam induces cellular apoptosis in human cancer cells and inhibits tumor growth in xenograft mice. Mol Cells 36: 219-226, 2013.

14. Young C, Jevtovic-Todorovic V, Qin YQ, Tenkova T, Wang H, Labruyere J and Olney JW: Potential of ketamine and midazolam, individually or in combination, to induce apoptotic neurodegeneration in the infant mouse brain. Br J Pharmacol 146: 189-197, 2005.

15. Stevens MF, Werdehausen R, Gaza N, Hermanns H, Kremer D, Bauer I, Küry P, Hollmann MW and Braun S: Midazolam activates the intrinsic pathway of apoptosis independent of benzodiazepine and death receptor signaling. Reg Anesth Pain Med 36: 343-349, 2011

16. Casellas P, Galiegue S and Basile AS: Peripheral benzodiazepine receptors and mitochondrial function. Neurochem Int 40: 475-486, 2002

17. Chiang T, Messing RO and Chou WH: Mouse model of middle cerebral artery occlusion. J Vis Exp: pii: 2761, 2011.

18. Longa EZ, Weinstein PR, Carlson S and Cummins R: Reversible middle cerebral artery occlusion without craniectomy in rats. Stroke 20: 84-91, 1989.
19. Livak KJ and Schmittgen TD: Analysis of relative gene expression data using real-time quantitative PCR and the 2(-Delta Delta C(T)) method. Methods 25: 402-408, 2001.

20. Young $C$ and Olney JW: Neuroapoptosis in the infant mouse brain triggered by a transient small increase in blood alcohol concentration. Neurobiol Dis 22: 548-554, 2006.

21. Wüllner U, Seyfried J, Groscurth P, Beinroth S, Winter S, Gleichmann M, Heneka M, Löschmann P, Schulz JB, Weller M and Klockgether T: Glutathione depletion and neuronal cell death: The role of reactive oxygen intermediates and mitochondrial function. Brain Res 826: 53-62, 1999.

22. Valencia A and Morán J: Reactive oxygen species induce different cell death mechanisms in cultured neurons. Free Radic Biol Med 36: 1112-1125, 2004.

23. Griffiths JD, Le NV, Grant S, Bjorksten A, Hebbard P and Royse C: Symptomatic local anaesthetic toxicity and plasma ropivacaine concentrations after transversus abdominis plane block for Caesarean section. Br J Anaesth 110: 996-1000, 2013.

24. Sakura S, Kirihara Y, Muguruma T, Kishimoto T and Saito Y: The comparative neurotoxicity of intrathecal lidocaine and bupivacaine in rats. Anesth Analg 101: 541-547, 2005.

25. Zhang DX, Ding HZ, Jiang S, Zeng YM and Tang QF: An in vitro study of the neuroprotective effect of propofol on hypoxic hippocampal slice. Brain Inj 28: 1758-1765, 2014

26. Liang C, Cang J, Wang H and Xue Z: Propofol attenuates cerebral ischemia/reperfusion injury partially using heme oxygenase-1. J Neurosurg Anesthesiol 25: 311-316, 2013.

27. Shao H, Zhang Y, Dong Y, Yu B, Xia W and Xie Z: Chronic treatment with anesthetic propofol improves cognitive function and attenuates caspase activation in both aged and Alzheimer's disease transgenic mice. J Alzheimers Dis 41: 499-513, 2014

28. Shi C, Zhao L, Zhu B, Li Q, Yew DT, Yao Z and Xu J: Protective effects of Ginkgo biloba extract (EGb761) and its constituents quercetin and ginkgolide B against beta-amyloid peptide-induced toxicity in SH-SY5Y cells. Chem Biol Interact 181: 115-123, 2009.

29. Bournival J, Quessy P and Martinoli MG: Protective effects of resveratrol and quercetin against MPP+-induced oxidative stress act by modulating markers of apoptotic death in dopaminergic neurons. Cell Mol Neurobiol 29: 1169-1180, 2009.

30. Chong WS, Hyun CL, Park MK, Park JM, Song HO, Park T, Lim YS, Cho CK, Kang PS and Kwon HU: Midazolam protects B35 neuroblastoma cells through Akt-phosphorylation in reactive oxygen species derived cellular injury. Korean J Anesthesiol 62: 166-171, 2012.

31. Satoh T, Nakatsuka D, Watanabe Y, Nagata I, Kikuchi H and Namura S: Neuroprotection by MAPK/ERK kinase inhibition with U0126 against oxidative stress in a mouse neuronal cell line and rat primary cultured cortical neurons. Neurosci Lett 288: $163-166,2000$

32. Stanciu M, Wang Y, Kentor R, Burke N, Watkins S, Kress G, Reynolds I, Klann E, Angiolieri MR, Johnson JW and DeFranco DB: Persistent activation of ERK contributes to glutamate-induced oxidative toxicity in a neuronal cell line and primary cortical neuron cultures. J Biol Chem 275: 12200-12206, 2000.

33. McCubrey JA, Steelman LS, Chappell WH, Abrams SL, Wong EW, Chang F, Lehmann B, Terrian DM, Milella M, Tafuri A, et al: Roles of the Raf/MEK/ERK pathway in cell growth, malignant transformation and drug resistance. Biochim Biophys Acta 1773: 1263-1284, 2007. 